\section{Fine-needle aspiration cytology of head and neck masses: Is ultrasound guidance routinely warranted?}

To the Editor: Fine-needle aspiration cytology (FNAC) is a simple, cheap and quick diagnostic procedure to differentiate infective from benign from malignant head and neck masses, and to direct management. ${ }^{[1]}$ It also reduces surgical interventions and surgeryrelated morbidity and anxiety. ${ }^{[2]}$

Palpation-guided FNAC has a high sensitivity, specificity and accuracy in excess of $90 \%$, and non-diagnostic rates are $<20 \%{ }^{[3]}$ However, routine use of ultrasound guidance has been advocated in FNAC of palpable masses, especially with palpable thyroid nodules. ${ }^{[4]}$

Oncology and otolaryngology trainees at some South African (SA) training hospitals no longer perform freehand, palpationguided FNAC of masses in the head and neck, but refer patients for ultrasound-guided FNAC (USGFNAC). One of us (JJF) has also noted this to be the case in the private sector. USGFNAC adds expense, time and hospital visits for patients and hospitals and places an additional burden on radiology and pathology resources.

We question whether freehand, palpation-guided FNAC of neck masses should be advocated, especially in resource-constrained settings such as SA, and whether it should be included as an entrustable professional activity (EPA) in workplace-based assessments of trainee surgeons and oncologists.

A retrospective observational study was done to determine the non-diagnostic rate of freehand, palpation-guided FNAC with palpable head and neck masses in an SA setting. All patients who underwent FNAC for palpable head and neck masses in JJF's surgical practice from 1 January 2014 to 31 December 2018 were included. A non-aspiration technique with a 23-gauge needle was used; only when there was a negative yield of material was an aspiration technique employed. Local anaesthesia was not used. The aspirate was ejected onto a glass microscope slide, a second microscope slide was used to smear the cellular material into a monolayer of cells, and a spray fixative was applied.

Of 281 aspirates, most were sampled from cervical lymph nodes (36\%) and other cervical masses (27\%) (Table 1). Thirty-seven aspirates were non-diagnostic (13\%). One hundred and fortytwo aspirates (51\%) were benign and $102(36 \%)$ were malignant. Pleomorphic adenoma or reactive nodes were the most common benign diagnoses, and primary or metastatic squamous cell carcinoma was the most common malignant diagnosis.

The $87 \%$ diagnostic yield of freehand palpation-guided FNAC achieved in this study is similar to that reported in a large metaanalysis by Gharib and Goellner ${ }^{[5]}(83 \%)$. Choong et al. ${ }^{[3]}$ found no statistically significant difference in non-diagnostic rates between palpation and USGFNAC when done for thyroid nodules $(5.0 \% \mathrm{v}$. $4.5 \% ; p=0.53)$.

While USGFNAC adds value for non-palpable masses, cystic masses with a small solid component and non-diagnostic palpation-guided FNAC, we believe that it should not be routinely used (unless available in the doctor's surgery) considering the high yield of freehand, palpationguided FNAC, as well as the expense, which in the USA is four times that of palpation-guided FNAC, ${ }^{[3]}$ and the training and equipment required, including maintenance and cost of the machines. ${ }^{[6]}$ Added to this is the need to prioritise use of available ultrasound machines and expertise for obstetrics and trauma in developing countries. ${ }^{[7]}$ USGFNAC also adds expense, time and hospital visits for both patients and hospitals, places an additional burden on radiology and pathology services, and causes diagnostic delays.
Table 1. Summary of palpation-guided fine-needle aspiration cytology results $(N=281)$

\begin{tabular}{ll}
\hline & $\boldsymbol{n}(\%)$ \\
\hline Total & $37(13)$ \\
Non-diagnostic & $142(51)$ \\
Benign & $102(36)$ \\
Malignant & \\
Subsites & $77(27)$ \\
Neck mass & $101(36)$ \\
Neck node & $45(16)$ \\
Parotid & $5(2)$ \\
Submandibular & $17(6)$ \\
Thyroid & $36(12)$ \\
Other & \\
Diagnosis & $55(20)$ \\
Metastatic SCC & $8(3)$ \\
Primary SCC & $15(5)$ \\
Reactive node & $27(10)$ \\
Pleomorphic adenoma & $37(13)$ \\
Non-diagnostic & $139(49)$ \\
Other & \\
SCC = squamous cell carcinoma. &
\end{tabular}

Factors other than ultrasound guidance may affect the nondiagnostic rate, such as the experience of the doctor performing the FNAC and the experience of the cytopathologist interpreting the biopsy. ${ }^{[8]}$ The rate of non-diagnostic FNAC is also influenced by the number of needle passes, with 10 - 15 deemed adequate. ${ }^{[9]}$ Learning and practising correct palpation-guided FNAC techniques should therefore be integral to training of oncologists and surgeons, and should form part of workplace-based assessment.

The results of this study support the use of freehand, palpationguided FNAC of neck masses, especially in resource-constrained settings such as SA. It should be included as an EPA in workplacebased assessments of trainee surgeons and oncologists.

\section{Gerrit Viljoen}

Registrar, Division of Otorhinolaryngology, Faculty of Health Sciences, University of Cape Town, South Africa

dr.gerrit.viljoen@gmail.com

\section{Nandi Viljoen}

Registrar, Division of Anatomical Pathology, Faculty of Health

Sciences, University of Cape Town, South Africa

\section{Ellen Bolding}

Consultant, Division of Anatomical Pathology, PathCare, Cape Town, South Africa

\section{Johannes J Fagan}

Professor and Chair, Division of Otorhinolaryngology, Faculty of Health Sciences, University of Cape Town, South Africa

\footnotetext{
1. Iacob A, Zazgyva A, Ormenişan A, Mezei T, Sin A, Tilinca M. Effectiveness of fine-needle aspiration cytology in the diagnosis of lateral cervical nonthyroid tumors. Medicine (Baltimore) 2016;95(31):e4448. https://doi.org/10.1097/MD.0000000000004448

2. Tandon S, Shahab R, Benton JI, Ghosh SK, Sheard J, Jones TM. Fine-needle aspiration cytology in a regional head and neck cancer center: Comparison with a systematic review and meta-analysis. Head
} Neck 2008;30(9):1246-1252. https://doi.org/10.1002/hed.20849 
3. Choong KC, Khiyami A, Tamarkin SW, McHenry CR. Fine-needle aspiration biopsy of thyroid nodules: Is routine ultrasound-guidance necessary? Surgery 2018;164(4):789-794. https://doi. org/10.1016/j.surg.2018.04.047

4. Danese D, Sciacchitano S, Farsetti A, Andreoli M, Pontecorvi A. Diagnostic accuracy of conventional versus sonography-guided fine-needle aspiration biopsy of thyroid nodules. Thyroid 1998;8(1):15-21 https://doi.org/10.1089/thy.1998.8.15

5. Gharib H, Goellner JR. Fine-needle aspiration biopsy of the thyroid: An appraisal. Ann Intern Med 1993;118(4):282-289. https://doi.org/10.7326/0003-4819-118-4-199302150-00007

6. Shah S, Bellows BA, Adedipe AA, Totten JE, Backlund BH, Sajed D. Perceived barriers in the use of ultrasound in developing countries. Crit Ultrasound J 2015:7:11. https://doi.org/10.1186/s13089$015-0028-2$
7. Sippel S, Muruganandan K, Levine A, Shah S. Review article: Use of ultrasound in the developing world. Int J Emerg Med 2011;4:72. https://doi.org/10.1186/1865-1380-4-72

8. Ghofani Meckmo D, Rimm DL The value of onsite adequacy ass . aspirations is a function of operator experience. Cancer Cytopathol 2006,108(2):110-113. https://doi. org $/ 10.1002 /$ cncr.21715

9. Rausch P, Nowels K, Jeffrey RB Jr. Ultrasonographically guided thyroid biopsy: A review with emphasis on technique. J Ultrasound Med 2001;20(1):79-85. https://doi.org/10.7863/jum.2001.20.1.79

S Afr Med J 2020;110(8):713-714. https://doi.org/10.7196/SAMJ.2020.v110i8.14898 